\title{
Stress-Temperature Effects on Peat Compression
}

\author{
James L. Hanson ${ }^{1}$, Tuncer B. Edil ${ }^{2}$, and Patrick J. Fox ${ }^{3}$
}

\begin{abstract}
Laboratory and field tests have shown that accelerated compression of peat soils occurs in response to moderate heating and an effective overconsolidation is produced on subsequent cooling. This phenomenon has been termed thermal precompression. In this study, long-term laboratory and field tests were conducted to investigate secondary compression behavior of peat as a function of stress and temperature. Stepstress and step-temperature compression tests were conducted on two peat soils. Dramatic effects were observed upon heating and cooling. A field test site in Middleton, Wisconsin, USA was constructed to test the thermal precompression concept for in situ peats. The site contained two instrumented embankments. The soils under one test embankment were left at ambient temperature conditions. The soils beneath the second embankment were heated for a one-year period using a circulating hot water system. An increase in temperature up to $20^{\circ} \mathrm{C}$ over ambient conditions was achieved at depths extending to $5 \mathrm{~m}$. Secondary compression rates for the heated embankment were up to 4 times greater than the corresponding rates for the unheated embankment. After the soils under the second embankment cooled for one year, a second lift of soil was applied to both embankments and subsequent settlement was monitored over a ten-year period. The relationship of rate of void ratio change during secondary compression as a result of temperature and stress changes is described. This is provided as a function of void ratio for the peat soils using laboratory tests and for in situ compression using the field test site data.
\end{abstract}

' Member, ASCE, Assistant Professor, Department of Civil Engineering, Lawrence Technological University, 21000 W. Ten Mile Rd., Southfield, MI 48075

${ }^{2}$ Member, ASCE, Professor, Department of Civil and Environmental Engineering, University of Wisconsin, 1415 Engineering Dr., Madison, WI 53706

${ }^{3}$ Associate Member, ASCE, Associate Professor, Department of Civil and

Environmental Engineering University of California, Los Angeles, CA 90095 


\section{Introduction}

Soft organic soils and peats often need improvement for various applications. Conventional ground improvement techniques such as preloading present difficulties when applied to soft soils. The large loads associated with preloading, for example, can cause failure of weak soils. Such problems can be avoided using staged construction, chemical stabilization, and ground reinforcement.

This study was conducted to evaluate a hybrid soft ground improvement technique for peats that involves simultaneous moderate ground heating and surcharge loading. The study consisted of laboratory tests and a field demonstration project. The effects of temperature and stress on secondary compression of peats are determined for laboratory and field conditions. The behavior is quantified using parameters that relate the variation of rate of void ratio change to stress and temperature.

\section{Background}

The compression behavior of peat varies from the compression behavior of other types of soils in two ways. First, peats generally compress more than other soils and second, the long-term (secondary compression) portion of settlement plays a more significant role in determining the total settlement of peats compared with other soil types. Secondary compression involves adjustment of the soil structure or soil skeleton under constant effective stress (i.e., after excess pore water pressures have dissipated). For many peats, primary consolidation is completed in a short time due to their typical high initial hydraulic conductivity. Therefore, secondary compression begins soon after loading and continues indefinitely. For peat soils, the e-log $t$ curve beyond end of primary consolidation is commonly non-linear showing an increase in slope with increasing time (Edil and Dhowian 1979).

The rate of secondary compression in soils is temperature dependent (Finn 1951). Campanella and Mitchell (1968) performed extensive consolidation tests using temperature-controlled triaxial equipment. The equipment allowed for testing at a range of temperatures from 20 to $60^{\circ} \mathrm{C}$. This testing program is the most definitive to date because it recognized two separate mechanisms of heating effects on consolidation: an increase in pore water pressure and a decrease in the viscosity of the soil skeleton. In general, secondary compression rate increases with increasing temperature. It has been shown that temperature effects are more prominent in normally consolidated clays than in overconsolidated clays (Leroueil 1994).

Thermal precompression is the process of heating a soil deposit under a surcharge load and then allowing it to return to ambient temperature. For peat, a large settlement has been observed to accompany this process followed by an overconsolidation effect in which the soil exhibits increased stiffness upon further loading (Fox 1992).

\section{Testing Program}

The testing program consisted of laboratory and field tests. The laboratory testing program included step-stress, step-temperature, and constant rate-of-strain tests. 


\section{Materials}

Tests were conducted on a fibrous peat and sedimentary peat taken at depths of approximately $2 \mathrm{~m}$ and $3 \mathrm{~m}$ below the ground surface at the field test site. The sedimentary peat is greenish-brown and is characterized by the presence of highly decomposed plant remains that resemble grass and leaves. The fibrous peat is brown, is less uniformly decomposed, and is characterized by the presence of roots and limbs. Both peats have an anisotropic fabric with elements generally oriented in the horizontal plane. Physical properties of both soils are given in Table 1 .

Table 1. Properties of Fibrous Peat and Sedimentary Peat

\begin{tabular}{|c|c|c|c|}
\hline $\begin{array}{c}\text { Physical } \\
\text { Property }\end{array}$ & $\begin{array}{c}\text { ASTM Test } \\
\text { Designation }\end{array}$ & $\begin{array}{c}\text { Fibrous } \\
\text { Peat }\end{array}$ & $\begin{array}{c}\text { Sedimentary } \\
\text { Peat }\end{array}$ \\
\hline Specific Gravity & D854 & 1.7 & 1.7 \\
\hline Initial Void Ratio & D2345 & $10 \pm 2$ & 7.41 \\
\hline Water Content & D2216 & $500-700 \%$ & $430-520 \%$ \\
\hline Organic Content & D2974 & $88-95 \%$ & $58-65 \%$ \\
\hline $\begin{array}{c}\text { Fiber Content } \\
\text { Wet Unit Weight } \\
\left(\mathrm{kN} / \mathrm{m}^{3}\right)\end{array}$ & D1997 & $30-60 \%$ & $20-30 \%$ \\
\hline $\begin{array}{c}\text { Dry Unit Weight } \\
\left(\mathrm{kN} / \mathrm{m}^{3}\right)\end{array}$ & D2345 & $10 \pm 0.4$ & $10.3 \pm 0.2$ \\
\hline $\begin{array}{c}\text { Von Post } \\
\text { Classification }\end{array}$ & D2345 & $1.25-1.88$ & $1.6-2.0$ \\
\hline $\begin{array}{c}\text { Preconsolidation } \\
\text { Pressure, } \sigma_{c}(\mathrm{kPa})\end{array}$ & $\begin{array}{c}\text { D 2345 } \\
\text { D 4186 }\end{array}$ & H3 & H6 \\
\hline pH & D2976 & $5.04 \pm 0.02$ & $6.06 \pm 0.03$ \\
\hline
\end{tabular}

\section{Laboratory Testing Program}

The objective of the laboratory testing program was to quantify the secondary compression behavior of fibrous peat and sedimentary peat. Peat samples were obtained from the field using $75 \mathrm{~mm}$-diameter Shelby tubes. Two methods of consolidation testing were used to obtain the desired parameters: the step-stress/steptemperature tests and constant rate-of-strain (CRS) tests. Samples were $63.5 \mathrm{~mm}$ in diameter and either $19 \mathrm{~mm}$ or $25 \mathrm{~mm}$ in height. Vertical deformations were monitored using dial gauges with a precision of $25 \mu \mathrm{m}$. Pore water pressures at the base of each specimen were monitored throughout each test.

The step-stress/step-temperature tests were conducted in temperature-controlled consolidometers. Fox and Edil (1996) provide details of the apparatus and testing method. For this procedure, specimens were subjected to incremental changes in stress and temperature. A loading and heating schedule was adopted that provided an assessment of the individual contributions of stress change and temperature change at various void ratios. Stress changes were applied at constant temperature and temperature changes were applied at constant stress. 
The load increments were applied using dead weights so that loads would be absolutely constant during long-term consolidation tests. Most of the step-stress testing involved consecutive steps of increasing stress. The loading schedule alternated between large load steps (Load Increment Ratio, LIR of approximately 0.6) and small load steps (LIR of approximately 0.1). The small load increments allowed for characterization of peat under varying normal loads at essentially the same void ratio. Load increment durations ranged from approximately 1 week to 10 weeks. Total consolidation test durations were approximately 23 months for most sedimentary peat tests and of various durations for fibrous peat with the longest tests extending to 2 years. The step-temperature tests consisted of subjecting a peat specimen to increasing or decreasing temperature steps during secondary compression. Temperatures were controlled using a closed-loop water circulation system. Typically, temperature steps of $10^{\circ} \mathrm{C}$ were applied to the peat specimens. Under normal operation, the variation in temperature of the circulation system was $\pm 1{ }^{\circ} \mathrm{C}$. Temperatures in the range of $15^{\circ} \mathrm{C}$ to $65^{\circ} \mathrm{C}$ were maintained for the consolidation tests. Durations of temperature steps were a function of the loading and heating schedule for each specimen, but generally ranged from 4 weeks to 12 weeks. Because the testing goals were primarily to characterize secondary compression behavior, the time required to reach end of primary (EOP) consolidation was determined for each load or temperature increment from pore water pressure measurements.

The CRS tests were conducted in conventional consolidometers at laboratory temperature $\left(20^{\circ} \mathrm{C} \pm 1^{\circ} \mathrm{C}\right)$ using strain rates from $4 \times 10^{-5} \mathrm{sec}^{-1}$ to $2 \times 10^{-7} \mathrm{sec}^{-1}$. These strain rates are faster than rates observed for long-term field compression.

Results are presented for the step-stress/step-temperature tests and the CRS tests. The dramatic impact of temperature on compression of fibrous peat is introduced with results from a step-stress/step-temperature test. Fox (1992) and Fox and Edil (1996) present detailed results for the fibrous peat tests. Results shown herein emphasize the sedimentary peat tests. A comparison of the influence of stress and temperature changes on the compression behavior of fibrous peat and sedimentary peat is included at the end of the paper.

The effect of thermal precompression on a laboratory specimen of fibrous peat is shown in Figure 1 for a step-stress/step-temperature test. A substantial increase of compression rate occurred as the specimen was heated from $14^{\circ} \mathrm{C}$ to $60^{\circ} \mathrm{C}$ at constant vertical stress. The secondary compression index, $\mathrm{C}_{\alpha}$ (slope of the e-log[t] line after EOP) is also substantially higher at the higher temperature. It can be seen that secondary compression was essentially arrested upon cooling the specimen from $60^{\circ} \mathrm{C}$ to $24^{\circ} \mathrm{C}$ that. Substantial increases in secondary compression rates of sedimentary peat under heated conditions were also observed by Hanson (1996). 


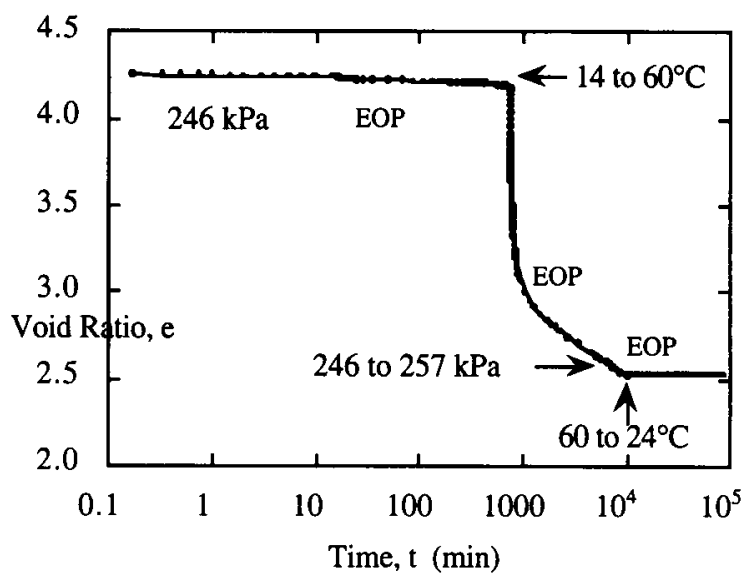

Figure 1. Laboratory Demonstration of Thermal Precompression of Fibrous Peat (Fox and Edil 1994)

The relationship between void ratio and void ratio rate (-de/dt) is presented in Figure 2 for load and temperature steps associated with one laboratory specimen of sedimentary peat undergoing a step-stress/step-temperature test. Large circles on this plot indicate EOP for each load or temperature step. Chronologically, the test data proceeds from right to left in Figure 2 (i.e., from high e to low e). A substantial increase in void ratio rate immediately follows application of both stress and temperature steps. The peak in void ratio rate due to application of stress or temperature diminishes in magnitude as the soil become further compressed.

Trends for the CRS tests on sedimentary peat are shown in Table 2 and Figure 3. Excess pore water pressures measured during the tests were considerably larger for the faster strain rates than the slower strain rates. A comparison of maximum pore pressures and preconsolidation stresses is shown in Table 2 for CRS tests on sedimentary peat. Variation of vertical strain with log effective stress is shown for all CRS tests on sedimentary peat in Figure 3. The apparent preconsolidation stress of sedimentary peat is observed to increase with increasing strain rate in a CRS consolidation test, similar to the behavior for inorganic clay soils (Tidfors and Sallfors 1989).

A unique effective stress-void ratio-void ratio rate relationship was investigated for all of these tests and is demonstrated for both fibrous peat and sedimentary peat (Lan 1992, Fox and Edil 1996, Hanson 1996). 


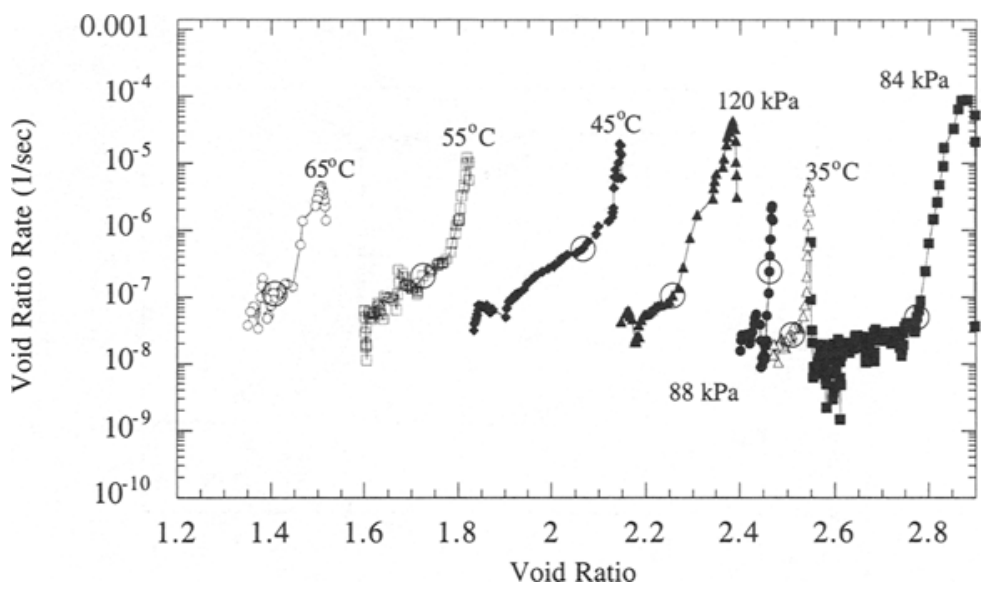

Figure 2. Void Ratio vs. Void Ratio Rate for Stress and Temperature Steps Applied to Sedimentary Peat (Hanson 1996)

Table 2. Summary of CRS Test Program Results for Sedimentary Peat

\begin{tabular}{|c|c|c|c|c|}
\hline $\begin{array}{c}\text { CRS } \\
\text { Test Number }\end{array}$ & $\begin{array}{c}\text { Approximate } \\
\text { Test } \\
\text { Duration }\end{array}$ & $\begin{array}{c}\text { Strain } \\
\text { Rate } \\
(1 / \mathrm{sec})\end{array}$ & $\begin{array}{c}\text { Maximum } \\
\Delta u \\
(\mathrm{kPa})\end{array}$ & $\begin{array}{c}\text { Preconsolidation } \\
\text { Stress } \\
(\mathrm{kPa})\end{array}$ \\
\hline BS3 & 50 minutes & $4.0 \times 10^{-3}$ & 640 & 18 \\
\hline BS4 & 9 hours & $1.1 \times 10^{-3}$ & 430 & 30 \\
\hline BS6 & 4 days & $1.5 \times 10^{-6}$ & 92 & 47 \\
\hline BS5 & 36 days & $2.0 \times 10^{-1}$ & 8 & 80 \\
\hline
\end{tabular}




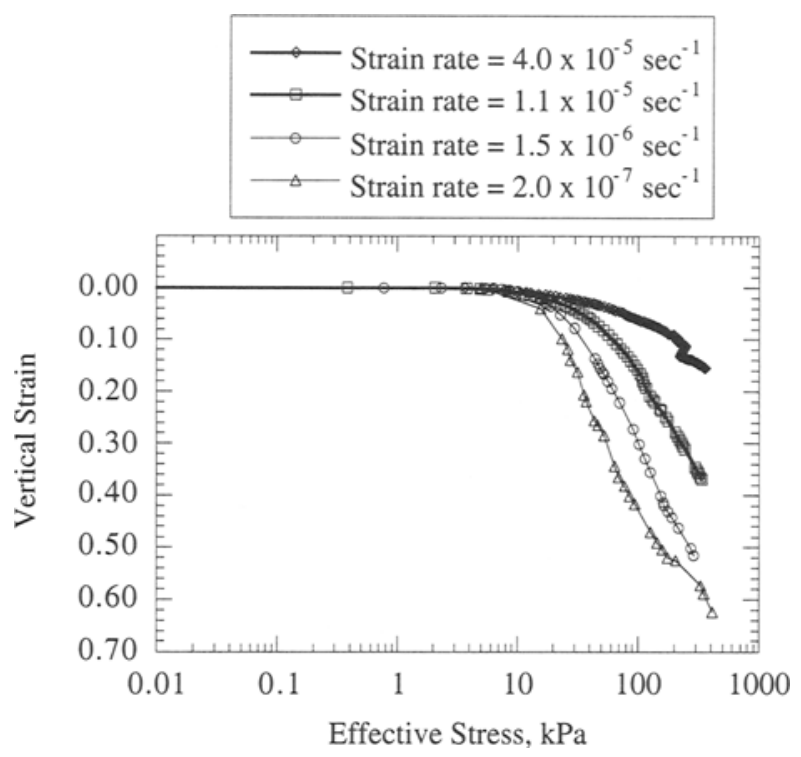

Figure 3. Strain vs. Logarithm of Effective Stress for Sedimentary Peat CRS Tests

Field Demonstration Project

The field site, located in Middleton, Wisconsin USA, contained two instrumented embankments. The project involved monitoring the settlement beneath both embankments to compare the consolidation behavior of peat soils at ambient ground temperature conditions (Test Fill A) and under conditions of in situ heating and natural cooling (Test Fill B). The unheated test fill was monitored for nearly 10 years. The heated test fill was monitored for approximately 6 years.

The test site consists of two $13 \mathrm{~m} \times 13 \mathrm{~m}$ compacted fill embankments over a common soil stratigraphy. Ground elevations and deformations, ground temperatures, and pore water pressures were monitored at different depths within the soil mass. Control and reference sites were located away from the fills to monitor the unloaded and unheated conditions at the site. A schematic plan view of the field site is shown in Figure 4. A soil profile with typical instrumentation is shown in Figure 5. Fibrous peat is present as a $0.8-\mathrm{m}$-thick layer below 1.5 -m-thick layer of surface silt. A $2-\mathrm{m}$ thick layer of sedimentary peat is below the fibrous peat. Underlying the peat layers is a $0.6-\mathrm{m}$-thick layer of organic silt and a 6.2-m-thick layer of marly silt.

Two lifts were constructed at Test Fill A, each lift $1.5 \mathrm{~m}$ high. The first lift was applied in November 1989 and the second lift was applied in June 1992. The ground was not heated under Test Fill A. Two lifts were also applied to Test Fill B, each $1.5 \mathrm{~m}$ high. The first lift at Test Fill B was applied in June 1992. Ground heating was initiated under Test Fill B in September 1992 and was terminated in October 1993. A second lift was applied to Test Fill B in October 1994 to assess the post-heating compression behavior at the site. Some residual heat content remained in 
the soil beneath Test Fill $B$ at the time of application of the second lift. The loading and heating schedules for the embankments are shown in Figure 6.

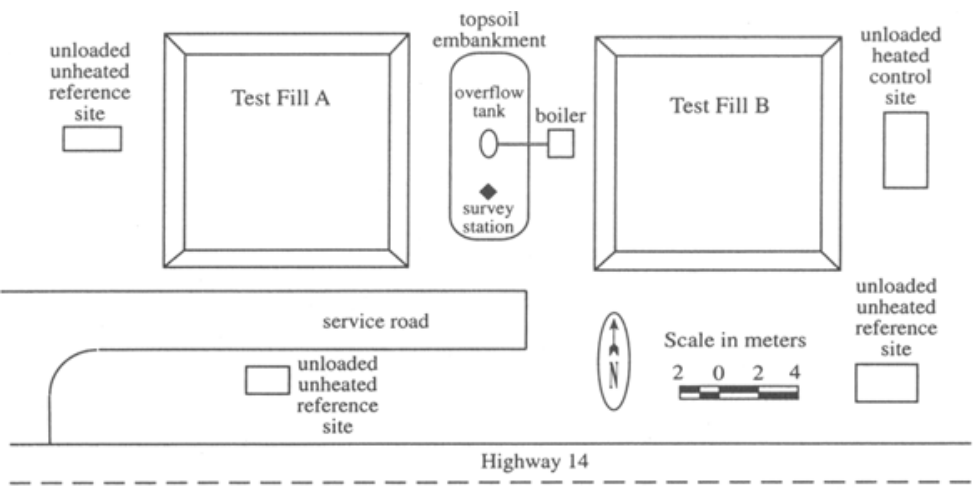

Figure 4. Plan View of Field Demonstration Site (Hanson 1996)

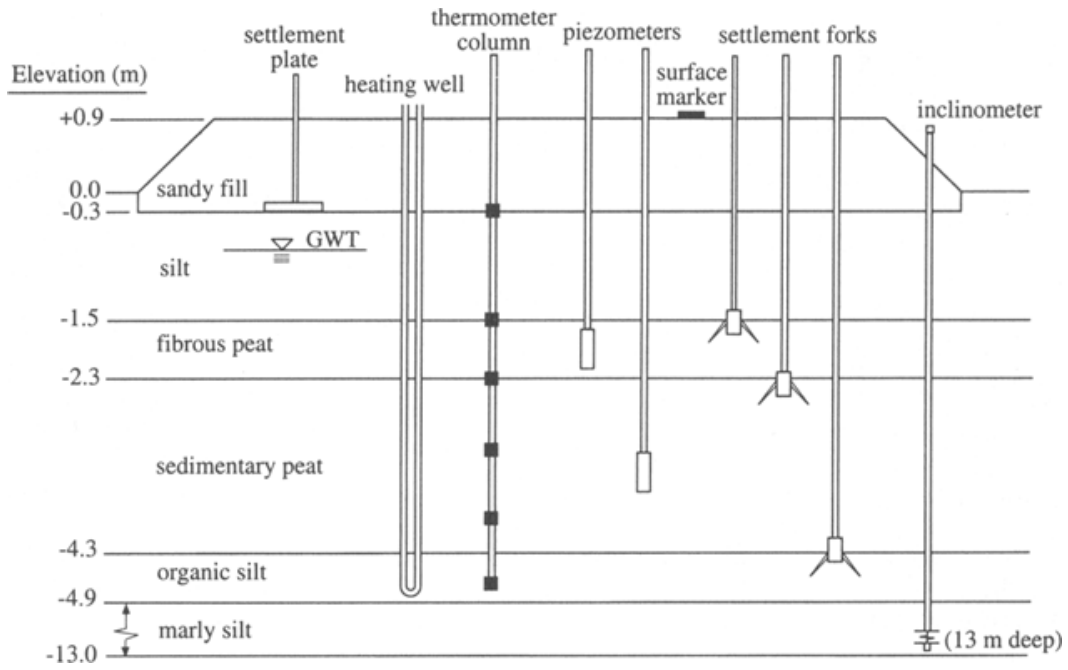

Figure 5. Vertical Cross Section of Typical Instrumentation and Soil Stratigraphy (Hanson 1995) 


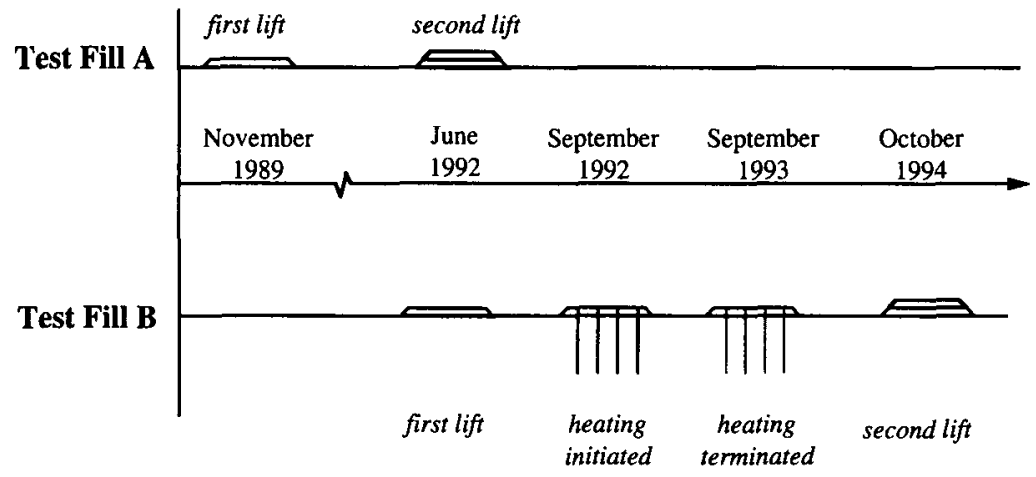

Figure 6. Loading and Heating Schedule at Field Demonstration Site.

The initial unheated consolidation period of Test Fill B (June to September 1992) allowed a direct comparison of the settlement for Test Fills A and B under ambient temperature conditions. The subsequent time-settlement curves for the test fills reflect the effects of heating and cooling of the ground on secondary compression rates (Figure 7a). Figure 7a shows a comparison of settlement of the test fills for the duration of the first lift of the loading sequence as measured by settlement plates (Figure 5). Settlements were larger beneath Test Fill B than Test Fill A. Although the compressibility at Test Fill B before application of heat was determined to be slightly greater than at Test Fill A, the difference in measured settlement was much larger during heated periods.

Settlement rate is defined as the instantaneous tangential slope of the settlement-time plot. A plot of settlement rate vs. time shows the dramatic effects due to heating (Figure $7 \mathrm{~b}$ ). Settlement rates greater than $1 \mathrm{~mm} /$ day occurred during primary consolidation at the test fills yet are not shown in Figures $7 \mathrm{~b}$ and 8 so that secondary compression can be presented with greater resolution. Settlement rates during peak heating periods for Test Fill B were up to 4 times greater than corresponding measured rates at Test Fill A. It also appears that secondary compression had slowed considerably during cooling periods due to mechanical problems with the heating system (approximately day 200 and day 300 ). The effects of these heating problems are evident in temperature and settlement rate at Test Fill B (Figure 7b). In addition to the response at Test Fill B, the secondary compression rates at Test Fill A also appear to be a function of seasonal ground temperatures. A parallel response of settlement rate and temperature can be observed due to the relatively small fluctuations of seasonal ground temperatures measured at a nearby unheated reference site (day 300-800 on Figure $7 \mathrm{~b}$ ). 


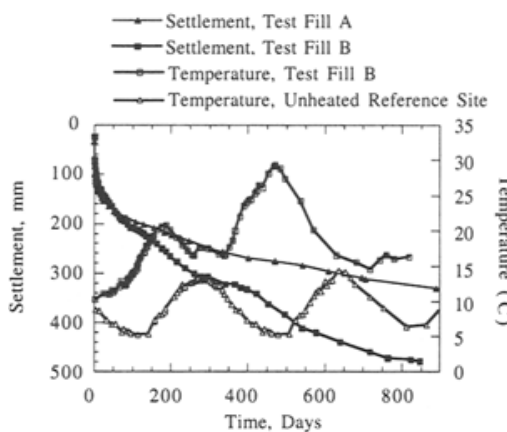

a) Settlement and Temperature

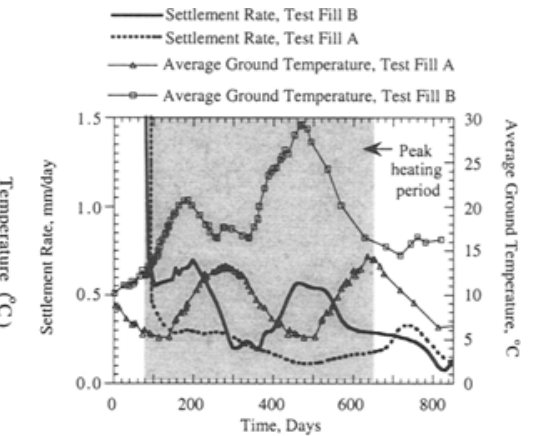

b) Settlement Rate and Temperature

Figure 7. Settlements Over Duration of the First Lift of Each Test Fill

Settlement rates for the entire two-lift loading sequence are shown in Figure 8 . The peak in settlement rate at days 850 and 940 corresponds to the placement of the second lift at each test fill. Increased rates of secondary compression are most pronounced during heating, although a slightly higher settlement rate is observed at Test Fill $B$ during the post-heating phase (Figure 8). The post-heating field compression behavior was different than what was demonstrated in the laboratory (where settlement was essentially arrested, Figure 1 by cooling) because rapid and uniform cooling was applied whereas in the field the soils were allowed to cool naturally. Residual heat remained in the ground for approximately 2 years after the active heating period. Settlement rates for the project duration indicate that the moderate ground heating was beneficial for attaining additional settlement at the site (as compared to unheated conditions). However, the settlement rates at Test Fill B did not show a dramatic decrease upon termination of heating (as was demonstrated in the laboratory). The compression behavior at the field site supports the use of ground heating to accelerate settlements, yet indicates the importance of post-compression cooling of the ground to induce the settlement arresting effect indicated by laboratory tests.

Continuous-sample borings were obtained from the center of each test fill and at an unloaded, unheated reference site in June 1997 to accurately assess layer interface elevations and determine properties of the layers. The borings beneath the test fills extended to a depth of $12 \mathrm{~m}$ and the boring at the unheated, unloaded reference site extended to $15 \mathrm{~m}$. The continuous samples were cut into $75 \mathrm{~mm}$ lengths to give the profiles of subsurface water content and organic content shown in Figure 9 (Reinicker 1998). 


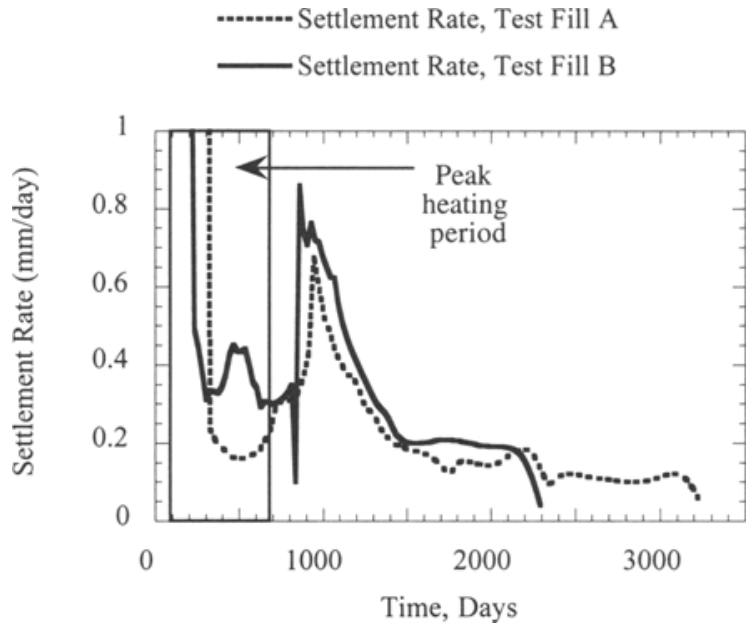

Figure 8. Settlement Rate vs. Time for Test Fill A and Test Fill B.
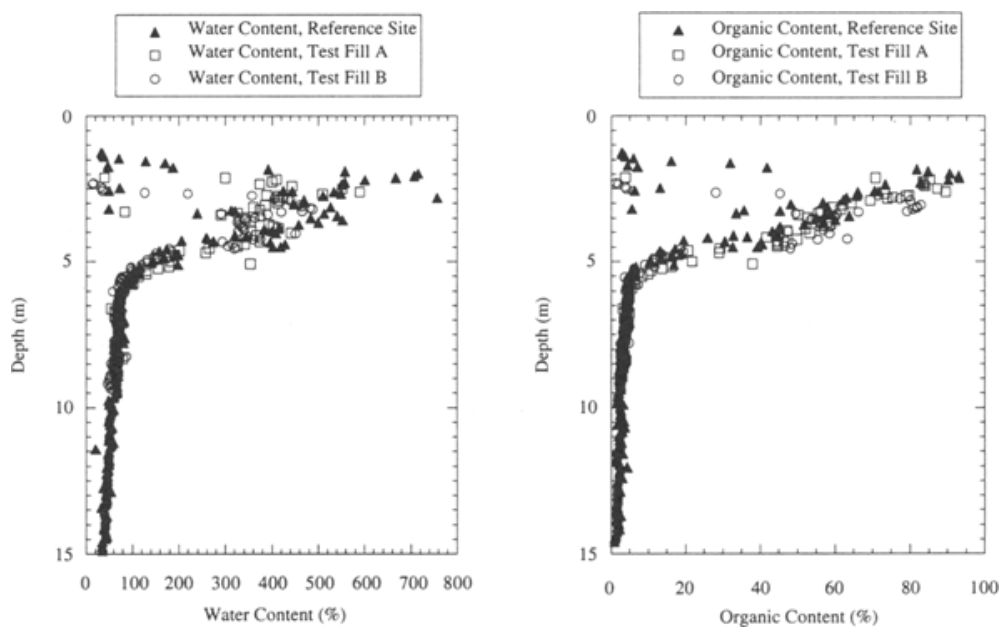

Figure 9. Water Content and Organic Content with Depth at Three Locations

Although organic content of laboratory sedimentary peat samples remained effectively unchanged over a 2.5 year heated testing period at elevated temperatures (Hanson 1996), the field data shows evidence of lower organic contents under the heated and loaded conditions (Figure 9). The consistently lower organic contents 
under heated conditions suggest increased rates of decomposition of the peats. MataAlvarez and Martinez-Viturtia (1986) reported that optimal biological degradation rates of municipal solid waste occur between temperatures from 36 to $38^{\circ} \mathrm{C}$. Mesri et al. (1997) and Fox et al. (1999) present the possible influence of biodegradation on secondary compression of organic soils. The effect of decomposition on secondary compression at the field site has not been verified experimentally in this study. In addition to lower organic contents, lower water contents are present beneath the test fills (due to consolidation of the soils) and the distribution of water content and organic content with depth is shifted downward (due to settlement of underlying soil layers).

\section{Prediction Parameters}

Fox and Edil (1996) presented a method for predicting response of fibrous peat (referred to as Middleton peat) to changes in temperature and stress. The method includes two parameters: stress coefficient of secondary compression, $C_{\sigma}$, and temperature coefficient of secondary compression, $C_{T}$ (Equations 1 and 2 ). The parameters can be used to quantify the change in void ratio rate due to stress and temperature changes during secondary compression. The relationships for these parameters as a function of void ratio are shown for fibrous peat, sedimentary peat, and general field response in Figure 10.

$$
\begin{aligned}
& C_{\sigma}=-\frac{\ln \dot{e}_{2}-\ln \dot{e}_{1}}{\sigma_{v_{2}}-\sigma_{v_{1}}^{\prime}}=-\frac{d \ln \dot{e}}{d \sigma^{\prime}{ }_{\nu}} \\
& C_{T}=-\frac{\ln \dot{e}_{2}-\ln \dot{e}_{1}}{T_{2}-T_{1}}=-\frac{d \ln \dot{e}}{d T}
\end{aligned}
$$

where $\dot{e}=$ void ratio rate $(-\mathrm{de} / \mathrm{dt}), \sigma_{v}{ }^{\prime}=$ vertical effective stress, and $T=$ temperature.

Fox (1992) determined that the temperature coefficient of secondary compression for fibrous peat is independent of void ratio and that the log of stress coefficient of secondary compression increases linearly with increasing void ratio. The general trends of the parameters are similar for sedimentary peat, although less data is available than for fibrous peat (Figure 10). The values of both parameters are generally larger and more scattered for sedimentary peat than for fibrous peat. Exponential best-fit curves were used to characterize the $C_{\sigma}$ data for each soil as:

$$
\begin{array}{ll}
C_{\sigma \text {-fibrous }}=0.0128^{*} \exp (0.367 \mathrm{e}) & {[1 / \mathrm{kPa}]} \\
C_{\sigma \text {-sedimentary }}=0.0311 * \exp (0.310 \mathrm{e}) & {[1 / \mathrm{kPa}]}
\end{array}
$$

These exponential curve fits are shown in Figure $10 \mathrm{a}$ and a line at $C_{T}=0.28 /{ }^{\circ} \mathrm{C}$ is provided for reference in Figure 10b. High values of $C_{T}$ and $C_{\sigma}$ result in large changes in $C_{\alpha}$ for a given stress or temperature change (Fox and Edil 1996). According to the parameter values determined in the laboratory, the sensitivity of secondary compression rate to both temperature and stress changes is greater for sedimentary peat than for fibrous peat. 

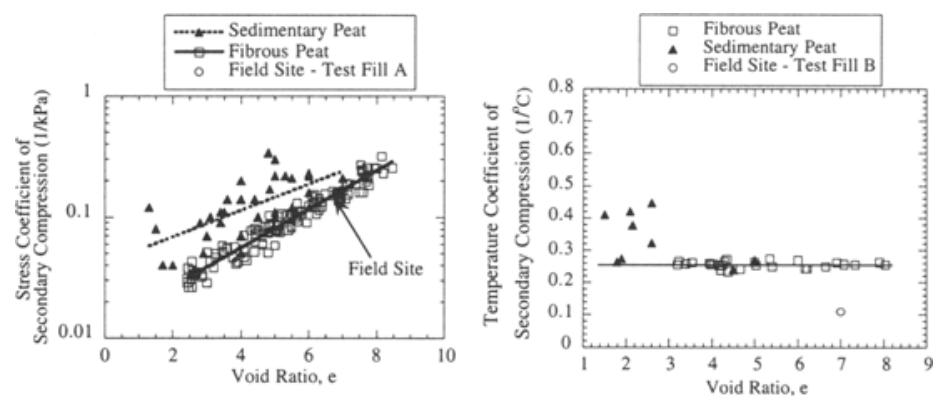

Figure 10. Variation in $C_{\sigma}$ and $C_{T}$ with Void Ratio for Fibrous Peat, Sedimentary Peat, and Field Site.

The heating period at the field test site was also used to determine $C_{\sigma}$ and $C_{r}$. The value of $C_{\sigma}$ from the field test is consistent with the laboratory data, whereas the value of $C_{T}$ is lower. Two reasons for the discrepancy in $C_{T}$ are the non-uniform heating conditions in the field (Fox and Edil 1996), and the impact of underlying soils on parameter determination. The underlying soils are less compressible than the peat layers and therefore would be expected to contribute less effect due to temperature changes during secondary compression. Due to problems with the layer-specific field instrumentation (settlement forks) [Hanson 1996], the parameters were determined using total settlement beneath the center of each test fill from settlement plate readings. These readings include deformations of all soil layers, preventing isolation of peatspecific values.

\section{Conclusions}

Conclusions are drawn from laboratory and field tests performed to investigate the long term secondary compression behavior of fibrous peat and sedimentary peat under conditions of changing stress and temperature. The field test involved monitoring settlements beneath two embankments, one at heated conditions and one at ambient temperature conditions. Parameters to quantify the effect of temperature and stress on settlement rate during secondary compression were determined. The following conclusions are drawn:

1) Sedimentary peat and fibrous peat display a similar behavior of accelerated void ratio rates during secondary compression under heated conditions in the laboratory. Load steps and temperature steps induce similar effects on the soil by increasing the void ratio rate of secondary compression. Subsequent rapid cooling causes a dramatic reduction in settlement. The magnitude of the peak void ratio rate that is observed due to application of stress or temperature step reduces with decreasing void ratio.

2) The apparent preconsolidation stress of sedimentary peat is observed to increase with increasing rate of compression in a constant-rate-of-strain consolidation test, similar to the behavior for inorganic clay soils. These results and the results of 
conventional tests on these peats were consistent with the unique effective stressvoid ratio-void ratio rate relationship proposed by Leroueil et al. (1985).

3) Stress and temperature coefficients of secondary compression, $C_{\sigma}$ and $C_{T}$, are larger for sedimentary peat than for fibrous peat. Therefore, the sensitivity of secondary compression rate to changes in temperature and stress is greater for sedimentary peat than for fibrous peat. $C_{\sigma}$ and $C_{T}$ determined from the field site are generally consistent with those determined in the laboratory.

(4) Field-scale ground heating for thermal precompression applications is feasible. A heating system circulating hot water can be used to raise ground temperatures beneath the embankment approximately $10-20^{\circ} \mathrm{C}$ above ambient temperature conditions.

(5) Settlement measurements indicate that the secondary compression rate of peats increases with heating and decreases with cooling in the field. The moderate heating applied in the current study caused an increase in the settlement rate of about 4 times as compared to the settlement rate of the unheated control fill. After the termination of heating, secondary compression settlements are reduced; but not as dramatically as indicated by laboratory test results because active cooling was not applied in the field. Increased rates of secondary compression are evident throughout the entire heated period in the field.

(6) Based on the dramatic acceleration of settlement at the heated fill, thermal precompression may offer an alternative for ground improvement when the economic conditions and time constraints render it favorable.

\section{Acknowledgment}

Mr. Norman Severson is remembered for his great service to this project. Mr. Keith Ligler, Mr. Morched Zeghal, and Mr. Li-Tus Lan assisted with surveying and collection of field data. Mr. Brian Reinicker tested the samples from the continuous sampling borings. Funding from the National Science Foundation (Grant \#MSS9115315) and the United States Federal Highway Administration is greatly appreciated.

\section{References}

Campanella, R. G. and Mitchell, J. K. (1968). "Influence of temperature variations on soil behavior," Journal of Soil Mechanics and Foundation Engineering Division, ASCE, Vol. 94, SM3, 709-734.

Edil, T. B. and Dhowian, A. W. (1979). "Analysis of long-term compression of peats," ASCE Journal of Geotechnical Engineering, Vol. 10, 159-178.

Edil, T. B. and Fox, P. J. (1994). "Field observations of thermal precompression of peat," Proceedings of Settlement '94: Vertical and Horizontal Deformations of Foundations and Embankments, Yeung, E.T. and Felio, G. Y., eds., ASCE Geotechnical Special Publication 40, Vol. 2, 1274-1286.

Finn, F.N. (1951). "The effect of temperature on the consolidation characteristics of remolded clay," ASTM STP 126, 65-71. 
Fox, P. J. and Edil, T. B. (1994). "Temperature-induced one-dimensional creep of peat," Advances in Understanding and Modelling the Mechanical Behaviour of Peat, Den Haan, E., Termaat, R., and Edil, T., eds. A. A. Balkema, Rotterdam, 1994.

Fox, P. J. and Edil, T. B. (1996). "Effects of stress and temperature on secondary compression behavior of peat," Canadian Geotechnical Journal 33, no. 3, 405-415.

Fox, P. J. (1992). "An analysis of one-dimensional creep of peat," Ph.D. Thesis, University of Wisconsin-Madison, Department of Civil and Environmental Engineering, Madison, Wisconsin.

Fox, P. J., Roy-Chowdhury, N., and Edil, T. B. (1999). "Secondary compression of peat with or without surcharging - Discussion," $A S C E$ Journal of Geotechnical and Geoenvironmental Engineering, Vol. 125, No. 2, 160-162.

Hanson, J. L. (1995). "Field demonstration of thermal precompression of peat," Proceedings 43rd Anmual Geotechnical Engineering Conference, University of Minnesota, Feb. 3, 1995, Minneapolis, Minnesota, 1-16.

Hanson, J. L. (1996). "Thermal precompression of peat," Ph.D. Thesis, University of Wisconsin-Madison, Department of Civil and Environmental Engineering, Madison, Wisconsin.

Lan, L. T. (1992). "A model for one-dimensional compression of peat," $P h . D$. Thesis, University of Wisconsin-Madison, Department of Civil and Environmental Engineering, Madison, Wisconsin.

Leroueil, S. (1994). "Compressibility of clays: fundamental and practical aspects," Proceedings of Settlement '94 Vertical and Horizontal Deformations of Foundations and Embankments, Edited by E.T. Yeung and G. Y. Felio, ASCE, Vol. 1, 57-76.

Leroueil, L., Kabbaj, M., Tavenas, F., and Bouchard, R. (1985). "Stress-strain-strain rate relation for the compressibility of sensitive natural clays," Geotechnique, $35: 2: 159-180$.

Mata-Alvarez, J. and Martinez-Viturtia, A. (1986). "Laboratory simulation of municipal solid waste fermentation with leachate recycle," Journal of Chemical Technology and Biotechnology, Vol. 36, 547-556.

Mesri, G., Stark, T. D., Ajlouni, M. A., and Chen, C. S. (1997). "Secondary compression of peat with or without surcharging," $A S C E$ Journal of Geotechnical and Geoenvironmental Engineering, Vol. 123, No. 5, 411-421.

Reinicker, B. (1998). "Consolidation and settlement of peats and organic soils" Masters Project Report, University of Wisconsin-Madison, Department of Civil and Environmental Engineering, Madison, Wisconsin.

Tidfors, M. and Sallfors, G. (1989). "Temperature effect on preconsolidation pressure," ASTM Geotechnical Testing Journal, Vol. 12, 93-97. 